\title{
HOW TO EFFECTIVELY BOOST FAT OXIDATION BY CALORIE RESTRICTION IN OVERWEIGHT AND OBESE ADULTS?
}

\author{
Rima Solianik, Artūras Sujeta, Kristina Justinavičienė, Laura Žlibinaitė \\ Lithuanian Sports University, Kaunas, Lithuania
}

\begin{abstract}
Background. It is clinically important to determine the factors that increase fat oxidation and have potential to improve body composition in overweight and obese individuals. Thus, the aim of the present study was to compare the effects of a 2-day very low-calorie diet and 2-day zero-calorie diet on fat oxidation and prospective food consumption in overweight and mildly obese adults.

Methods. Eighteen subjects (body mass index above $25 \mathrm{~kg} / \mathrm{m}^{2}$ ) aged 19-33 years were tested under two conditions allocated randomly: 2-day zero-calorie diet with water provided ad libitum and 2-day very-low calorie diet. Appetite sensations, mood state, inhibitory control, and substrate oxidation were evaluated before and after each diet.

Results. Greater increase in fat oxidation $(p<.05)$ was observed after zero-calorie diet when compared to a very low-calorie diet. Results showed that both diets increased $(p<.05)$ sensation of hunger and prospective food consumption, whereas no changes were observed in inhibitory control. Greater decrement for vigor $(p<.05)$ was observed after zero-calorie diet when compared to a very low-calorie diet, whereas other mood states were not affected by it.

Conclusion. Intermittent fasting with zero-calorie diet may boost fat oxidation to a greater extent when compared to very low-calorie diet and may assist with weight loss in overweight and mildly obese adults.
\end{abstract}

Keywords: fasting, inhibitory control, mood, substrate oxidation very-low calorie diet.

\section{INTRODUCTION}

I nterventions aimed at increasing fat metabolism could reduce the symptoms of metabolic diseases such as obesity and type 2 diabetes. Thus, it is clinically important to determine the factors that increase fat oxidation (Achten \& Jeukendrup, 2004; Frisancho, 2003) and have potential to improve body composition in overweight and obese individuals. Different degrees of calorie restriction regimes are important determinants of fat oxidation. It is well established that increased ketosis can burn stored fat and to produce the energy needed by the body and brain (Anton et al., 2018; Cox \& Clarke, 2017). Recently, 5:2 intermittent calorie restriction has been popularized, in which a very low-calorie diet or zero-calorie diet is allowed 2 days a week and "normal" eating is resumed on non-diet days (Anton et al., 2018; Longo \& Mattson, 2014; Solianik \& Sujeta, 2018; Solianik, Sujeta, \& Čekanauskaite, 2018; Solianik, Sujeta, Terentjevienè, \& Skurvydas, 2016). Nevertheless, recent studies showed that low glucose level is replaced by ketones (Cunnane et al., 2011), and glucose availability depends on the degree of calorie restriction (Solianik \& Sujeta, 2018; Solianik et al., 2018; Solianik et al., 2016), we are not aware of any previous studies of the comparison of a 2-day zero-calorie diet and 2-day very low calorie diet on fat oxidation.

It is noteworthy that successful weight loss depends on inhibitory control that is particularly important in the maintenance of obesity-related behaviors and potentially, differential response to interventions. Recent studies observed that poor 
general inhibitory control is associated with reduced weight loss outcomes (Manasse et al., 2017). It was established that neither 2-day zero-calorie diet (Solianik \& Sujeta, 2018), nor 2-day very low-calorie diet (Solianik et al., 2018) affected inhibitory control. However, dietary adherence might also be limited by perceived stress, mood and appetite sensation changes. Higher food intake in response to stress and negative emotions is an important factor of the weight regain of many dieters (Van Strien, 2018). Recent studies established that feelings of emptiness and hunger were associated with a dysphoric mood (Solianik et al., 2016; Hetherington et al., 2013). It was established that both very-low calorie diet and zero-calorie diet evoke moderate stress (Solianik \& Sujeta, 2018; Solianik et al., 2018). However, only zero-calorie diet increases anger in amateur weight lifters (Solianik et al., 2016) and decreases the sensation of vigor in overweight women even before the start of the diet (Solianik \& Sujeta, 2018). Interestingly, despite of increase in hunger after zero-calorie diet (Solianik \& Sujeta, 2018; Solianik et al., 2016) and very low-calorie diet (Solianik et al., 2018), it can be expected that increased ketones after fasting may coincide decrease in hunger (White \& Venkatesh, 2011).

Nevertheless, it can be expected that a zerocalorie diet has greater efficiency in fat oxidation compared to a very low-calorie diet. Yet, subjective responses, such as hunger, desire to eat and mood degradation, might limit further weight loss. Therefore, the main aim of present study was to compare the effects of a 2-day very low-calorie diet and zero-calorie diet on fat oxidation and prospective food consumption in overweight and mildly obese adults. Moreover, inhibitory control, perceived stress responses, mood state and appetite sensations, such as hunger and fullness, were also examined.

\section{METHODS}

Participants. Twenty-six volunteers were assessed for eligibility. The criteria for inclusion were: (1) overweight or mildly obese (BMI 25-35 kg/m²) adults; (2) age $18-35$ years; (3) nonsmokers; (4) not engaged in any weight reduction program; (5) no excessive sporting activities, i.e., $\leq 3$ times per week; (6) no medications that could affect experimental variables; (7) no history of chronic disease. Pregnant or lactating women were excluded. In total, eighteen participants
( 8 men and 10 women) aged $26.4 \pm 4.5$ years met the inclusion criteria and agreed to participate in this study. Informed consent was obtained from all participants included in the study. All procedures were approved by the Kaunas Regional Biomedical Research Ethics Committee (No. BE-2-5) and were conducted in accordance with the Declaration of Helsinki.

Experimental protocol. We used a paired crossover design, in which all participants participated in two experimental parts in a randomized order, at least 1 week apart. One week before the experiment, all participants were familiarized with the inhibitory control tasks. The participants were instructed to refrain from fatiguing work, and from ingesting alcoholic beverages, caffeine, and sedating antihistamines for at least 2 days before the experimental measurements.

All experimental measurements began at 8:00 a. $\mathrm{m}$. The participant arrived at the laboratory after overnight fasting. Upon arrival at the laboratory, body weight was measured. The participant was then asked to rest and remain awake while lying supine for $20 \mathrm{~min}$ in a quiet room. Resting pulmonary gas exchange was recorded during the last $10 \mathrm{~min}$. Subsequently, the participant rated current mood and appetite sensations, and a blood sample was obtained for measurement of glucose concentration. The participant was then seated at a table, and inhibitory control evaluating tasks were performed. The participant then rested 1 day before starting the 2-day very low-calorie diet (511 kcal/day) or the 2-day zero-calorie diet with water provided ad libitum as described previously (Solianik \& Sujeta, 2018; Solianik et al., 2018; Solianik et al., 2016). Briefly, during the very low-calorie diet, commercially available instant oatmeal porridge (Activus, Kauno Grūdai, Kaunas, Lithuania) was packaged in $70.0 \mathrm{~g}$ (dry weight) packages, and two packages per day were provided to each participants for 2 days. Each package had a caloric content of $255.5 \mathrm{kcal}$. The composition of the oatmeal was $47.4 \mathrm{~g}$ carbohydrates (10.3 g sugars), $10.9 \mathrm{~g}$ protein, $3.8 \mathrm{~g}$ total fat ( $0.8 \mathrm{~g}$ saturated fat), $5.0 \mathrm{~g}$ dietary fibers, and $0.1 \mathrm{~g}$ salt. After both 2-day diets, the participant arrived at the laboratory after an overnight fast, and provided their subjective rating of perceived stress and repeated the experimental measurements in the same order as that described for the period before dieting.

Experimental measurements. The body weight and body mass index (BMI) were measured 
using a body composition scale (model number TBF-300, Tanita, West Drayton, UK) while the participants were wearing only underwear.

Oxygen uptake $\left(\mathrm{VO}_{2}\right)$ and carbon dioxide production $\left(\mathrm{VCO}_{2}\right)$ were monitored every $5 \mathrm{~s}$ on a breath-by-breath basis using the mobile spirometry system (Oxycon Mobile, Jaeger/ VIASYS Healthcare, Hoechberg, Germany), which was calibrated following the manufacturer's instructions. Total carbohydrate (CHO) and fat oxidation (FO) rates were computed using the following non-protein stoichiometric equations (Péronnet \& Massicotte, 1991): $\mathrm{CHO}=4.585 \times$ $\mathrm{VCO}_{2}-3.226 \times \mathrm{VO}_{2}$, and $\mathrm{FO}=1.695 \times \mathrm{VO}_{2}-$ $1.701 \times \mathrm{VCO}_{2}$. Respiratory exchange ratio $(\mathrm{RER}=$ $\mathrm{VCO}_{2} / \mathrm{VO}_{2}$ ) was also used to determine substrate oxidation.

Mood states were assessed using the Brunel Mood Scale containing 24 items (Terry, Lane, \& Fogarty, 2003). The items are answered on a 5-point scale ranging from 0 (not at all) to 4 (extremely), and each subscale (i.e. anger, confusion, depression, fatigue, tension, and vigor), with four relevant items, can achieve a raw score in the range of 0 to 16 .

Appetitesensations (hunger, fullness, prospective food consumption and desire to eat specific foods) were assessed on a visual analogue scale ranging from 0 ("I am not hungry at all/not at all full/nothing at all/very much") to 10 ("I have never been more hungry/totally full/a lot/not at all") on a 10-cm long horizontal line (Flint, Raben, Blundell, \& Astrup, 2000). Perceived stress was also assessed on a visual analogue scale ranging from 0 ("no stress") to 100 ("the highest stress imaginable") (Solianik \& Sujeta, 2018; Solianik et al., 2018).

The glucose concentrations were determined in capillary blood samples using a CardioChek PA analyzer (Polymer Technology Systems Inc, Indianapolis, IN, USA) via finger-prick test.

Inhibitory control was assessed using the computerized automated neuropsychological assessment metric Version 4 (Vista Life Sciences, Parker, CO, USA) (Reeves, Winter, Bleiberg, \& Kane, 2007). During Go/No-Go task, the participant was instructed to respond as quickly as possible to a letter " $x$ " on the screen by pressing the right button each time the stimulus appeared; when a letter "o" appeared, the participant was required to withhold his response. During Stroop task, the participant was instructed to respond as quickly as possible to the color used to print the color names on the screen by pressing an associated keyboard key (1 for "red", 2 for "green", and 3 for "blue").
On each trial, a word indicating a color name was presented on the screen in different color ink (i.e. red, green, or blue).

Statistical analysis. All values are presented as means \pm standard deviations. A two-way repeated measures analysis of variance with two withinsubject factors was used to analyze the effects of time (before vs. after) and diet (zero-calorie diet vs. very low-calorie diet) on all variables. If a significant effect of time, diet or time-diet interaction was found, the statistical power (SP) and the partial eta squared $\left(\mathrm{n}_{P}^{2}\right)$ were calculated as an indication of the magnitude of the observed effect. If a significant interaction of time $\times$ diet was observed, a paired t-test was used to identify the changes within each diet and to evaluate the differences between diets. The dependent-sample t-test was also used to determine differences in the perceived stress ratings between diets. The level of significance was set at $p<0.05$. Statistical analysis was carried out using Statistical Package for Social Sciences (SPSS) software version 21.0 (IBM Corp., Armonk, NY, USA).

\section{RESULTS}

Anthropometry. The anthropometric parameters of the participants are reported in Table 1. Significant effects of time $\left(F_{1,17}=169.27, p<.001\right.$, $S P=1.00, \mathrm{\eta}_{P}^{2}=0.91$ for weight and $F_{1,17}=163.46, p<$ $.001, S P=1.00, \mathrm{\eta}_{P}^{2}=0.91$ for BMI) and the time $\times$ diet interaction $\left(F_{1,17}=5.63, p=.030, S P=0.61, \mathrm{\eta}_{P}^{2}=\right.$ 0.25 for weight and $F_{1,17}=4.56, p=.048, S P=0.52$, $\mathrm{\eta}_{P}^{2}=0.21$ for $\mathrm{BMI}$ ) were observed for anthropometric data. Participants in the zero-calorie diet and very low-calorie diet lost $(p<.001) \quad 2.2 \pm 0.9 \mathrm{~kg}$ and $1.7 \pm 0.8 \mathrm{~kg}$ of initial weight, and $0.7 \pm 0.3 \mathrm{~kg} / \mathrm{m}^{2}$ and $0.5 \pm 0.2 \mathrm{~kg} / \mathrm{m}^{2}$ of initial BMI, respectively. Greater decrement for weight $(p=.033)$ and BMI $(p=.022)$ was observed after zero-calorie diet when compared to very low-calorie diet.

Perceived stress and appetite sensations. The perceived stress during the zero-calorie diet and very low-calorie diet was rated as moderate $(42.0 \pm 19.3$ and $39.7 \pm 20.6$, respectively); it did not differ between diets. The appetite sensations of the participants are reported in Table 2. Both diets decreased sensation of fullness $\left(F_{1,17}=60.72, p<.001\right.$, $\left.S P=1.00, \mathrm{\eta}_{P}^{2}=0.78\right)$, and increased sensation of hunger $\left(F_{1,17}=69.96, p<.001, S P=1.00, \mathrm{\eta}_{P}^{2}=0.80\right)$ and prospective food consumption $\left(F_{1,17}=22.19\right.$, $\left.p<.001, S P=0.99, \mathrm{\eta}_{P}^{2}=0.57\right)$. Participants indicated an increased desire to eat sweet $\left(F_{1,17}=9.19, p=.008\right.$, 
$\left.S P=0.82, \mathrm{n}_{P}^{2}=0.35\right)$, salty $\left(F_{1,17}=11.16, p=.004\right.$, $\left.S P=0.88, \eta_{P}^{2}=0.40\right)$, and savory foods $\left(F_{1,17}=18.26\right.$, $\left.p=.001, S P=0.98, \mathrm{y}_{P}^{2}=0.52\right)$. The significant time $\times$ diet interaction was observed only for fullness $\left(F_{1,17}=\right.$ $\left.5.49, p=.032, S P=0.60, \mathrm{\eta}_{P}^{2}=0.24\right)$. The zero-calorie diet and very low-calorie diet significantly decreased sensation of fullness $(p<.003) 3.2 \pm 2.2$ and $1.4 \pm 1.7$ of initial sensation, respectively. Greater decrement for fullness $(p=.002)$ was observed after zerocalorie diet when compared to very low-calorie diet.
Mood states. The mood states of the participants are reported in Table 3. The significant time $\times$ diet interaction was observed only for vigor $\left(F_{1,17}=5.49, p=.038, S P=0.60, \mathrm{\eta}_{P}^{2}=0.24\right)$. The zero-calorie diet significantly decreased vigor $(p=$ .040) $1.7 \pm 3.2$ of initial state, whereas this state remained unchanged during the very low-calorie diet. Greater decrement for vigor $(p=.038)$ was observed after zero-calorie diet when compared to very low-calorie diet.

Table 1. The effect of 2-day diets on the anthropometry

\begin{tabular}{|c|c|c|c|c|c|c|c|c|c|c|c|}
\hline & \multicolumn{4}{|c|}{ Zero-calorie diet } & \multicolumn{4}{|c|}{ Very low-calorie diet } & \multirow{3}{*}{$\begin{array}{c}\text { Effect of } \\
\text { diet }\end{array}$} & \multirow{3}{*}{$\begin{array}{l}\text { Effect of } \\
\text { time }\end{array}$} & \multirow{3}{*}{$\begin{array}{l}\text { Interaction } \\
\text { effect of time } \\
\times \text { diet }\end{array}$} \\
\hline & \multicolumn{2}{|c|}{ Before } & \multicolumn{2}{|c|}{ After } & \multicolumn{2}{|c|}{ Before } & \multicolumn{2}{|c|}{ After } & & & \\
\hline & Mean & $S D$ & Mean & $S D$ & Mean & $S D$ & Mean & $S D$ & & & \\
\hline Weight, kg & 87.6 & 12.9 & 86.3 & 12.8 & 86.9 & 12.5 & 85.2 & 12.2 & n. s. & $p<.001$ & $p=.030$ \\
\hline BMI, $\mathrm{kg} / \mathrm{m}^{2}$ & 27.7 & 2.3 & 27.0 & 2.2 & 27.5 & 2.2 & 26.9 & 2.2 & n. s. & $p<.001$ & $p=.048$ \\
\hline
\end{tabular}

Notes. $S D$, standard deviation; BMI, body mass index; n. s., not significant $(p>.05)$.

Table 2. The effect of 2-day diets on the appetite sensations

\begin{tabular}{|c|c|c|c|c|c|c|c|c|c|c|c|}
\hline & \multicolumn{4}{|c|}{ Zero-calorie diet } & \multicolumn{4}{|c|}{ Very low-calorie diet } & \multirow{3}{*}{$\begin{array}{c}\text { Effect of } \\
\text { diet }\end{array}$} & \multirow{3}{*}{$\begin{array}{l}\text { Effect of } \\
\text { time }\end{array}$} & \multirow{3}{*}{$\begin{array}{l}\text { Interaction } \\
\text { effect of time } \\
\times \text { diet }\end{array}$} \\
\hline & \multicolumn{2}{|c|}{ Before } & \multicolumn{2}{|c|}{ After } & \multicolumn{2}{|c|}{ Before } & \multicolumn{2}{|c|}{ After } & & & \\
\hline & Mean & $S D$ & Mean & $S D$ & Mean & $S D$ & Mean & $S D$ & & & \\
\hline Hunger & 3.9 & 2.4 & 7.3 & 2.3 & 4.0 & 2.3 & 6.2 & 2.0 & n. s. & $p<.001$ & n. s. \\
\hline Fullness & 3.9 & 2.3 & 0.8 & 0.9 & 3.8 & 1.4 & 2.4 & 1.6 & n. s. & $p<.001$ & $p=.032$ \\
\hline $\begin{array}{l}\text { Prospective food } \\
\text { consumption }\end{array}$ & 5.8 & 1.9 & 7.7 & 1.5 & 5.6 & 1.9 & 6.9 & 1.7 & n. s. & $p<.001$ & n. s. \\
\hline \multicolumn{12}{|l|}{$\begin{array}{l}\text { Desire to eat } \\
\text { foods: }\end{array}$} \\
\hline Sweet & 6.4 & 2.5 & 4.3 & 2.8 & 6.2 & 2.4 & 5.0 & 2.8 & n. s. & $p=.008$ & n. s. \\
\hline Salty & 6.4 & 2.2 & 4.1 & 2.5 & 6.1 & 2.3 & 4.5 & 2.5 & n. s. & $p=.004$ & n. s. \\
\hline Savory & 7.4 & 2.7 & 4.9 & 3.7 & 7.6 & 2.4 & 5.8 & 3.4 & n. s. & $p<.001$ & n. s. \\
\hline Fatty & 7.8 & 2.6 & 6.0 & 3.9 & 6.3 & 3.4 & 6.5 & 3.5 & n. s. & n. s. & n. s. \\
\hline
\end{tabular}

Notes. SD, standard deviation; n. s., not significant $(p>.05)$.

Table 3. The effect of 2-day diets on the mood states

\begin{tabular}{|c|c|c|c|c|c|c|c|c|c|c|c|}
\hline & \multicolumn{4}{|c|}{ Zero-calorie diet } & \multicolumn{4}{|c|}{ Very low-calorie diet } & \multirow{3}{*}{$\begin{array}{c}\text { Effect of } \\
\text { diet }\end{array}$} & \multirow{3}{*}{$\begin{array}{l}\text { Effect of } \\
\text { time }\end{array}$} & \multirow{3}{*}{$\begin{array}{l}\text { Interaction } \\
\text { effect of time } \\
\times \text { diet }\end{array}$} \\
\hline & \multicolumn{2}{|c|}{ Before } & \multicolumn{2}{|c|}{ After } & \multicolumn{2}{|c|}{ Before } & \multicolumn{2}{|c|}{ After } & & & \\
\hline & Mean & SD & Mean & SD & Mean & SD & Mean & SD & & & \\
\hline Anger & 0.5 & 0.9 & 1.5 & 1.9 & 0.9 & 1.6 & 0.9 & 1.3 & n. s. & n. s. & n. s. \\
\hline Confusion & 1.2 & 2.4 & 1.4 & 2.1 & 1.2 & 2.1 & 0.6 & 0.9 & n. s. & n. s. & n. s. \\
\hline Depression & 0.6 & 1.5 & 1.3 & 1.9 & 1.3 & 2.2 & 1.0 & 1.5 & n. s. & n. s. & n. s. \\
\hline Fatigue & 4.2 & 3.3 & 5.4 & 4.1 & 4.3 & 3.3 & 3.4 & 2.8 & n. s. & n. s. & n. s. \\
\hline Tension & 1.6 & 1.8 & 1.6 & 1.5 & 1.2 & 1.4 & 1.3 & 1.7 & n. s. & n. s. & n. s. \\
\hline Vigor & 8.6 & 1.9 & 6.9 & 3.5 & 7.2 & 3.2 & 7.9 & 3.3 & n. s. & n. s. & $p=.038$ \\
\hline
\end{tabular}

Notes. SD, standard deviation; n. s., not significant $(p>.05)$. 
Table 4. The effect of 2-day diets on the inhibitory control

\begin{tabular}{|c|c|c|c|c|c|c|c|c|c|c|c|}
\hline & \multicolumn{4}{|c|}{ Zero-calorie diet } & \multicolumn{4}{|c|}{ Very low-calorie diet } & \multirow{3}{*}{$\begin{array}{l}\text { Effect } \\
\text { of diet }\end{array}$} & \multirow{3}{*}{$\begin{array}{l}\text { Effect } \\
\text { of time }\end{array}$} & \multirow{3}{*}{$\begin{array}{c}\text { Interaction } \\
\text { effect of } \\
\text { time } \times \text { diet }\end{array}$} \\
\hline & \multicolumn{2}{|c|}{ Before } & \multicolumn{2}{|c|}{ After } & \multicolumn{2}{|c|}{ Before } & \multicolumn{2}{|c|}{ After } & & & \\
\hline & Mean & SD & Mean & SD & Mean & SD & Mean & SD & & & \\
\hline \multicolumn{12}{|l|}{ Go/No-Go task } \\
\hline Reaction time, ms & 334.5 & 21.5 & 336.4 & 24.6 & 340 & 26.3 & 334.9 & 16.7 & n. s. & n. s. & n. s. \\
\hline Accuracy, \% & 94.1 & 3.3 & 94.3 & 3.9 & 94.4 & 3.2 & 94.4 & 2.7 & n. s. & n. s. & n. s. \\
\hline \multicolumn{12}{|l|}{ Stroop task } \\
\hline Reaction time, ms & 590.5 & 93.3 & 585.3 & 109.7 & 584.5 & 108.1 & 581.7 & 109.5 & n. s. & n. s. & n. s. \\
\hline Accuracy, \% & 94.9 & 4.5 & 93.8 & 6.6 & 94.4 & 5.3 & 92.4 & 5.9 & n. s. & n. s. & n. s. \\
\hline
\end{tabular}

Notes. $S D$, standard deviation; n. s., not significant $(p>.05)$.

Table 5. The effect of 2-day diets on the glucose level and substrate oxidation

\begin{tabular}{|c|c|c|c|c|c|c|c|c|c|c|c|}
\hline & \multicolumn{4}{|c|}{ Zero-calorie diet } & \multicolumn{4}{|c|}{ Very low-calorie diet } & \multirow{3}{*}{$\begin{array}{l}\text { Effect } \\
\text { of diet }\end{array}$} & \multirow{3}{*}{$\begin{array}{c}\text { Effect } \\
\text { of time }\end{array}$} & \multirow{3}{*}{$\begin{array}{l}\text { Interaction } \\
\text { effect of } \\
\text { time } \times \text { diet }\end{array}$} \\
\hline & \multicolumn{2}{|c|}{ Before } & \multicolumn{2}{|c|}{ After } & \multicolumn{2}{|c|}{ Before } & \multicolumn{2}{|c|}{ After } & & & \\
\hline & Mean & $S D$ & Mean & $S D$ & Mean & $S D$ & Mean & $S D$ & & & \\
\hline Glucose, mmol/l & 5.3 & 0.5 & 4.2 & 0.5 & 5.4 & 0.5 & 5.0 & 0.5 & $p<.001$ & $p<.001$ & $p=.009$ \\
\hline $\mathrm{VO}_{2}, 1 / \mathrm{min}$ & 0.25 & 0.04 & 0.27 & 0.05 & 0.26 & 0.05 & 0.25 & 0.05 & n. s. & n. s. & $p=.024$ \\
\hline $\mathrm{VCO}_{2}, 1 / \mathrm{min}$ & 0.21 & 0.03 & 0.20 & 0.04 & 0.21 & 0.04 & 0.19 & 0.04 & n. s. & $p=.003$ & n. s. \\
\hline RER & 0.84 & 0.08 & 0.71 & 0.03 & 0.81 & 0.04 & 0.74 & 0.02 & n. s. & $p<.001$ & $p=.008$ \\
\hline $\mathrm{CHO}, \mathrm{g} / \mathrm{min}$ & 0.16 & 0.09 & 0.02 & 0.04 & 0.14 & 0.05 & 0.05 & 0.04 & n. s. & $p<.001$ & $p=.012$ \\
\hline FO, g/min & 0.07 & 0.04 & 0.13 & 0.02 & 0.08 & 0.02 & 0.11 & 0.02 & n. s. & $p<.001$ & $p<.001$ \\
\hline
\end{tabular}

Notes. $S D$, standard deviation; $\mathrm{VO}_{2}$, oxygen uptake; $\mathrm{VCO}_{2}$, carbon dioxide production; $\mathrm{CHO}$, carbohydrate oxidation; FO, fat oxidation; n. s., not significant $(p>.05)$.

Inhibitory control. Data of inhibitory control requiring tasks are reported in Table 4 . There was no significant effect of time and diet, or the time $\times$ diet interaction on the inhibitory control.

Glucose level. Data of glucose level are reported in Table 5. Significant effect of time $\left(F_{1,17}=21.98\right.$, $\left.p<.001, S P=0.99, \mathrm{\eta}_{P}^{2}=0.61\right)$, diet $\left(F_{1,17}=58.93\right.$, $\left.p<.001, S P=1.00, \mathrm{\eta}_{P}^{2}=0.81\right)$, and time $\times \operatorname{diet}$ interaction $\left(F_{1,17}=9.35, p=.009, S P=0.81, \mathrm{\eta}_{P}^{2}=\right.$ $0.40)$ was observed for glucose level. Both diets significantly increased glucose level $(p<.001)$. A greater glucose level was observed after the very low-calorie diet compared to zero-calorie diet.

Substrate oxidation. Data of substrate oxidation are reported in Table 5. Significant effect of time $\left(F_{1,17}=85.26, p<.001, S P=1.00, \mathrm{\eta}_{P}^{2}=0.83\right.$ for RER, $F_{1,17}=93.80, p<.001, S P=1.00, \mathrm{\eta}_{P}^{2}=0.85$ for $\mathrm{CHO}$ and $\mathrm{F}_{1,17}=93.51, p<.001, S P=1.00, \mathrm{n}_{P}^{2}=$ 0.85 for FO) and time $\times$ diet interaction $\left(F_{1,17}=9.00\right.$, $p=.008, S P=0.81, \mathrm{n}_{P}^{2}=0.35$ for RER, $F_{1,17}=7.96$, $p=.012, S P=0.76, \mathrm{\eta}_{P}^{2}=0.32$ for $\mathrm{CHO}$ and $F_{1,17}=$ 14.99, $p<.001, S P=0.95, \mathrm{\eta}_{P}^{2}=0.47$ for FO) was observed for substrate oxidation. Both diets significantly increased FO $(p<.001)$, and decreased RER $(p<.001)$ and CHO $(p<.001)$. A greater FO, and lower RER and $\mathrm{CHO}$ were observed after the zero-calorie diet compared to very low-calorie diet.

\section{DISCUSSION}

The aim of the present study was to compare the effects of a 2-day different degree calorie restriction on fat oxidation and dietary adherence in overweight and mildly obese adults. Vigor decreased only after zero-calorie diet, while the effect on other mood states, perceived stress, hunger and inhibitory control did not differ between diets, causing similar responses on prospective food consumption and desire to eat specific foods. Fat oxidation increased 
after both diets; however, the increase was greater after zero-calorie diet.

Substrate oxidation. In accordance with previous studies (Clayton, Creese, Skidmore, Stensel, \& James, 2016; Horton \& Hill, 2001; Weyer, Vozarova, Ravussin, \& Tataranni, 2001; Zinker, Britz, \& Brooks, 1990), we have established that zero-calorie diet and very low-calorie diet increase fat oxidation (i.e. increase FO and decrease RER (i.e. the RER was close to 0.7 indicating that mainly fat was metabolized (Frisancho, 2003)) and decrease carbohydrate oxidation. As expected, greater fat oxidation was observed after zero-calorie diet. It is well established that with the inadequate availability of carbohydrates, the metabolism shifts from lipid/cholesterol synthesis and fat storage to mobilization of fat in the form of fatty acid and fatty acid-derived ketones, which provides energy to the body and the brain (Anton et al., 2018; Gupta et al., 2017). Thus it can be expected, that lower availability of energy during fasting state, caused greater fat oxidation during zero-calorie diet rather than very low-calorie diet.

Appetite sensations. It is suggested that stress can cause changes in appetite sensation (Farr, Li, \& Mantzoros, 2016). In the current study, both diets evoked similar moderate stress. As expected, both diets increased hunger and decreased fullness. Even though fullness was lower after zero-calorie diet, no differences were observed in hunger sensation between zero-calorie diet and very-lowcalorie diet. It is well established that low glucose level is replaced by ketones (Cunnane et al., 2011), and ketones may suppress hunger sensation (White \& Venkatesh, 2011). In the current study, lower glucose level was observed after-zero calorie diet when compared to very-low calorie diet. Thus, it might be expected that greater ketones increase masked increase in hunger after zero-calorie diet. Furthermore, similar increase in hunger after both diets coincides with similar prospective food consumption and desire to eat specific foods.

Mood states. It was established that depressive symptoms and anger are related to overeating and binge eating behavior (Skinner, Haines, Austin, \& Field, 2012; Zeeck, Stelzer, Linster, Joos, \& Hartmann, 2011). However, in accordance with previous studies (Solianik \& Sujeta, 2018; Solianik et al., 2018), only the zero-calorie diet decreased sensation of vigor in overweight and obese adults, whereas other mood states were not affected by it. In contrast, in previous study of Solianik et al. (2016), total calorie deprivation increased anger in amateur weight lifters. It was well established that resistance exercises increase testosterone level (Kraemer et al., 1999; Nindl et al., 2001), which may explain increased anger (O'Connor, Archer, \& Wu, 2004; Solianik et al., 2016) in weight lifters but not in overweight and mildly obese adults.

Inhibitory control. It was demonstrated that poorer inhibitory control causes overeating and temptation to eat tasty and high caloric food, which is associated with future weight gain and decreased capacity to maintain weight loss (Ziauddeen, Alonso-Alonso, Hill, Kelley, \& Khan, 2015; Nederkoorn, Jansen, Mulkens, \& Jansen, 2007). In accordance with previous studies (Solianik \& Sujeta, 2018; Solianik et al., 2018), very low-calorie diet and zero-calorie diet had no effect on inhibitory control in overweight and obese adults.

Limitations. Firstly, it should be noted that our subjects were overweight and mildly obese youngadults. Thus, the findings associated with the 2-day diets cannot be applied to other populations, such as children, older adults, lean or severely obese subjects. Secondly, the study was limited by the use of VAS for measurement of prospective food consumption and evaluation of lost weight at the end of both diets. Future studies should investigate maintenance of lost weight and estimate calorie intake after both diets.

\section{CONCLUSIONS}

Together, these findings suggest that effort to maintain weight losses are unlikely to be different between zero-calorie diet and verylow calorie diet, given current data of inhibitory control, emotional state, and appetite sensations. However, fat oxidation as a factor responsible for weight loss was greater after zero-calorie diet. Thus, intermittent fasting with zero-calorie diet may boost fat oxidation to a greater extent when compared to very low-calorie diet and assist with weight loss in overweight and mildly obese adults. Future studies should aim to compare chronic effects of different degree calorie restriction diets on weight loss-related indicators.

Acknowledgments. We thank joint-stock company Kauno Grūdai for supply of the food. 


\section{REFERENCES}

Achten, J., \& Jeukendrup, A. E. (2004). Optimizing fat oxidation through exercise and diet. Nutrition, 20(7-8), 716-727. doi: 10.1016/j.nut.2004.04.005

Anton, S. D., Moehl, K., Donahoo, W. T., Marosi, K., Lee, S., Mainous, A. G., ... Mattson, M. P. (2018). Flipping the metabolic switch: Understanding and applying health benefits of fasting. Obesity, 26(2), 254 268. doi: $10.1002 /$ oby. 22065

Clayton, D. J., Creese, M., Skidmore, N., Stensel, D. J., \& James, L. J. (2016). No effect of $24 \mathrm{~h}$ severe energy restriction on appetite regulation and ad libitum energy intake in overweight and obese males. International Journal of Obesity, 40(11), 1662-1670. doi: 10.1038/ ijo.2016.106

Cox, P. J., \& Clarke, K. (2017). Acute nutritional ketosis: Implications for exercise performance and metabolism. Extreme Physiology \& Medicine, 3, 17. doi: 10.1186/2046-7648-3-17

Cunnane, S., Nugent, S., Roy, M., Courchesne-Loyer, A., Croteau, E., Tremblay, S. C., ... Rapoport, S. (2011). Brain fuel metabolism, aging, and Alzheimer's disease. Nutrition, 27(1), 3-20. doi: 10.1016/j.nut.2010.07.021

Farr, O. M., Li, C. R., \& Mantzoros, C. S. (2016). Central nervous system regulation of eating: Insights from human brain imaging. Metabolism, 65(5), 699713. doi: 10.1016/j.metabol.2016.02.002

Flint, A., Raben, A., Blundell, J. E., \& Astrup, A. (2000). Reproducibility, power and validity of visual analogue scales in assessment of appetite sensations in single test meal studies. International Journal of Obesity, 24(1), 38-48. doi: 10.1038/sj.ijo.0801083

Frisancho, A. R. (2003). Reduced rate of fat oxidation: A metabolic pathway to obesity in the developing nations. American Journal of Human Biology, 15(4), 522-532. doi: 10.1002/ajhb.10191

Gupta, L., Khandelwal, D., Kalra, S., Gupta, P., Dutta, D., \& Aggarwal, S. (2017). Etogenic diet in endocrine disorders: Current perspectives. Journal of Postgraduate Medicine, 63(4), 242-251. doi: 10.4103/ jpgm.JPGM_16_17

Hetherington, M. M., Cunningham, K., Dye, L., Gibson, E. L., Gregersen, N. T., Halford, J. C., ... Van Trijp, H. C. (2013). Potential benefits of satiety to the consumer: Scientific considerations. Nutrition Research Reviews, 26(1), 22-38. doi: 10.1017/ S0954422413000012

Horton, T. J., \& Hill, J. O. (2001). Prolonged fasting significantly changes nutrient oxidation and glucose tolerance after a normal mixed meal. Journal Applied Physiology, 90(1), 155-163. doi: 10.1152/ jappl.2001.90.1.155

Kraemer, W. J., Häkkinen, K., Newton, R. U., Nindl, B. C., Volek, J. S., McCormick, M., . . . Evans, W. J. (1999). Effects of heavy-resistance training on hormonal response patterns in younger vs. older men. Journal Applied Physiology, 87(3), 982-992. doi: 10.1152/ jappl.1999.87.3.982

Longo, V. D., \& Mattson, M. P. (2014). Fasting: Molecular mechanisms and clinical applications. Cell Metabolism, 19(2), 181-192. doi: 10.1016/j.cmet.2013.12.008

Manasse, S. M., Flack, D., Dochat, C., Zhang, F., Butryn, M. L., \& Forman, E. M. (2017). Not so fast: The impact of impulsivity on weight loss varies by treatment type. Appetite, 113, 193-199. doi: 10.1016/j. appet.2017.02.042

Nederkoorn, C., Jansen, E., Mulkens, S., \& Jansen, A. (2007). Impulsivity predicts treatment outcome in obese children. Behaviour Research and Therapy, 45(5), 10711075. doi: 10.1016/j.brat.2006.05.009

Nindl, B. C., Kraemer, W. J., Gotshalk, L. A., Marx, J. O., Volek, J. S., Bush, F.A., ... Fleck, S. J. (2001). Testosterone responses after resistance exercise in women: Influence of regional fat distributioon. International Journal of Sport Nutrition and Exercise Metabolism, 11(4), 451465. doi: 10.1123/ijsnem.11.4.451

O’Connor, D. B., Archer, J., \& Wu, F. C. (2004). Effects of testosterone on mood, aggression, and sexual behavior in young men: A double-blind, placebo-controlled, cross-over study. Journal of Clinical Endocrinology and Metabolism, 89(6), 2837-2845. doi: 10.1210/jc.2003031354

Péronnet, F., \& Massicotte, D. (1991). Table of nonprotein respiratory quotient: An update. Canadian Journal of Sport Sciences, 16(1), 23-29.

Reeves, D. L., Winter, K. P., Bleiberg, J., \& Kane, R. L. (2007). ANAM genogram: Historical perspectives, description, and current endeavors. Archives of Clinical Neuropsychology, 22 (Suppl. 1), S15-37. doi: 10.1016/j. acn.2006.10.013

Skinner, H. H., Haines, J., Austin, S. B., \& Field, A. E. (2012). A prospective study of overeating, binge eating, and depressive symptoms among adolescent and youngadult women. Journal of Adolescent Health, 50(5), 478483. doi: 10.1016/j.jadohealth.2011.10.002

Solianik, R., Sujeta, A., \& Čekanauskaitè, A. (2018). Effects of 2-day calorie restriction on cardiovascular autonomic response, mood, and cognitive and motor functions in obese young adult women. Experimental Brain Research, 236(8), 2299-2308. doi: 10.1007/ s00221-018-5305-4

Solianik, R., \& Sujeta, A. (2018). Two-day fasting evokes stress, but does not affect mood, brain activity, cognitive, psychomotor, and motor performance in overweight women. Behavioural Brain Research, 338, 166-172. doi: 10.1016/j.bbr.2017.10.028

Solianik, R., Sujeta, A., Terentjevienè, A., \& Skurvydas, A. (2016). Effect of $48 \mathrm{~h}$ fasting on autonomic function, brain activity, cognition, and mood in amateur 
weight lifters. BioMed Research International, 1503956. doi: 10.1155/2016/1503956

Terry, P. C., Lane, A. M., \& Fogarty, G. J. (2003). Construct validity of the Profile of Mood States-Adolescents for use with adults. Psychology of Sport \& Exercise, 4, 125139. doi: 10.1016/S1469-0292(01)00035-8

Van Strien, T. (2018). Causes of emotional eating and matched treatment of obesity. Current Diabetes Reports, 18(6), 35. doi: 10.1007/s11892-018-1000-x

Weyer, C., Vozarova, B., Ravussin, E., \& Tataranni, P. A. (2001). Changes in energy metabolism in response to $48 \mathrm{~h}$ of overfeeding and fasting in Caucasians and Pima Indians. International Journal of Obesity and Related Metabolic Disorders, 25(5), 593-600. doi: 10.1038/ sj.ijo.0801610
White, H., \& Venkatesh, B. (2011). Clinical review: Ketones and brain injury. Critical Care, 15(2), 219. doi: $10.1186 / \mathrm{cc} 10020$

Zeeck, A., Stelzer, N., Linster, H. W., Joos, A., \& Hartmann, A. (2011). Emotion and eating in binge eating disorder and obesity. European Eating Disorders Review, 19(5), 426-437. doi: 10.1002/erv.1066

Ziauddeen, H., Alonso-Alonso, M., Hill, J. O., Kelley, M., \& Khan, N. A. (2015). Obesity and the neurocognitive basis of food reward and the control of intake. Advances in Nutrition, 6(4), 474-486. doi: 10.3945/an.115.008268 Zinker, B. A., Britz, K., \& Brooks, G. A. (1990). Effects of a 36-hour fast on human endurance and substrate utilization. Journal of Applied Physiology, 69(5), 18491855. doi: 10.1152/jappl.1990.69.5.1849
Corresponding author Rima Solianik Lithuanian Sports University Sporto str. 6, Kaunas LT-44221 Lithuania Tel. +37060695214

Email rima.solianik@1su.1t 